Commentary on: The Effect of Integrating Music Listening With an Attachment- and Affective-Focused Short-Term Psychotherapy in an Individual With Relational Trauma: The Case of "James"

\title{
Integrating Client-Chosen Music in Relational Trauma Treatment: Pathways to the Heart
}

\author{
KAREN RIGGS SKEAN ${ }^{\text {a,b }}$ \\ ${ }^{\text {a }}$ Graduate School of Applied and Professional Psychology, Rutgers University-New Brunswick, NJ \\ ${ }^{b}$ Correspondence regarding this article should be sent to Karen Riggs Skean, Graduate School of Applied and \\ Professional Psychology, Rutgers University-New Brunswick, 152 Frelinghuysen Road, Piscataway, NJ 08854 \\ Email: kskean@connect.rutgers.edu \\ Editor's Note: Karen Riggs Skean is a licensed psychologist with over 30 years in full-time private practice in \\ Highland Park, NJ, working with individuals and couples. In addition, for the last 25 years she has been on the \\ Clinical Psychology Faculty of the Graduate School of Applied and Professional Psychology at Rutgers University \\ in teaching and clinical supervisory roles, including teaching and supervising in the AEDP model. In addition, she \\ has specialized training and interests in Emotionally Focused Couple Therapy and Eye Movement Desensitization \\ and Reprocessing (EMDR) Therapy.
}

\begin{abstract}
This commentary discusses the therapy of a hybridized client (Blimling, 2019) with a difficult relational trauma history in which client-chosen music was combined with a short-term treatment utilizing Accelerated Experiential Dynamic Psychotherapy (AEDP). This combination bypassed rigid defenses and allowed access to a level of affect not ordinarily available to the client, allowing significant symptomatic and relational shifts to occur. Primary goals of helping the client deal with a major loss, reduce his level of depression, and improve his interpersonal functioning were met. Implications for the use of integrative methods with short-term models and the importance of therapist flexibility are discussed.
\end{abstract}

Key Words: Accelerated Experiential Dynamic therapy (AEDP); complex trauma; short-term dynamic psychotherapy; music; psychotherapy integration; case study; clinical case study

I worked with Dr. Blimling during his graduate training, both as the instructor for the advanced course in Short-Term Dynamic Psychotherapy and as a member of his dissertation committee, a dissertation which forms the basis for the current case study (Blimling, 2019). It was a pleasure to watch him develop his therapeutic skills in short-term work and at the same time be able to combine the models we were studying with a practicum placement that allowed him to use another important facet of who he is - his deep knowledge of and connection with music. A talented cellist who, had he taken another road, might have been a professional musician, he was in an excellent position to explore the integration of shared musical experience into short-term dynamic work. 


\section{SOME CROSS-CASE COMPARISONS: HELPING THE THERAPIST TO BE MORE PRESENT}

I (Skean, 2018) recently commented on a short-term therapy conducted by Vigoda Gonzalez (2018), which integrated Accelerated Experiential Dynamic Psychotherapy (AEDP) with a multicultural framework, using a shared language to enhance connection and increase access to affect, and wanted to touch upon some similarities to and differences from the current work. Vigoda Gonzalez' paper was a detailed account of her work with a relationally traumatized person and was an excellent showcasing of some key AEDP interventions as they were used to build the alliance, deepen affect and achieve a significantly positive outcome.

Blimling's case study is hybridized, not a single case, which offers both advantages and limitations. In addition to the client confidentiality it assures, it also allows him to condense the experience of several clients into one compelling narrative that demonstrates the integration of music into therapeutic work, and thus is "true" in the way that literature is true, rather than a detailed presentation of one actual case. Working for a year in a setting supporting his use of music in therapy, while simultaneously learning and applying short-term dynamic work, the current work reflects a crystallization of that experience. Other elements are similar to Vigoda Gonzalez' work - both clients would be viewed as having suffered serious early relational trauma, both were treated using AEDP interventions that emphasized attachment and affect, and both therapists found unique pathways to reach their wounded clients.

Reflecting on these two cases as well as an earlier PCSP study by Pass (2012), which combined AEDP with an expressive writing intervention, the lesson is not that there is some ideal combination of interventions that would necessarily become the basis for a new protocol. It is rather that the therapist in each case found some way of taking something core about themselves (Vigoda Gonzalez' bilingual identity and cultural sensitivity, Blimling's musicianship, Pass' former career as a writer and editor) and integrated it into their work in an enlivening way, both to the client and to themselves. This integrated method helped the therapist be more fully present with the client which in turn helped the client be more present as well, a "true self to a true other" as Fosha would put it.

\section{THE ROLE OF MUSIC IN THE CASE OF JAMES}

AEDP's focus on affect, present experience, and attachment theory framed Blimling's conceptualization of the use of music within each stage of his therapy. The model's incorporation of interpersonal neurobiology, emotion theory and bodily-focused trauma approaches (Fosha, 2000, 2006, 2018; Lipton and Fosha, 2011) is particularly relevant to his insession work with music. There is something physical and body-centered about our experience of music, a direct channel that can sometimes bypass the defenses we erect against hurt and anxiety. Oliver Sacks expressed this beautifully as he wrote about the power of music to "release grief and allow emotion to flow again" in discussing its being an antidote to states of depression and emotional numbing:

Music can pierce the heart directly; it needs no mediation.... And there is, finally a deep and mysterious paradox here, for while such music makes one experience pain and grief more intensely, it brings solace and consolation at the same time (Sacks, 2008, p. 301) 
We see this power to "pierce the heart" strikingly in the case of James. A severely traumatizing childhood left him with access to few emotions except a fierce anger and resentment that alienated him from others in a relentless cycle of aloneness and rejection. He entered treatment after the sudden death of his most important attachment figure, his sister, and only because his rage threatened the only other relationship that held any potential for him, his niece. His niece stated she could not maintain any relationship with him if he did not seek therapy.

Entering therapy only because of this threat and with little expectation that anything of value to him would occur as he was critical and contemptuous of his young therapist (Blimling), James agreed to bringing in a song that meant something to him to their third session. The way this was framed to James was important, simply that it was a way to get to know him better. This served as an invitation to self-expression less defended against than speaking directly about his life, which he was not yet willing to do. It also signaled flexibility on the therapist's part, a willingness to join with him in less formal ways and a curiosity about who he was.

The song he brought in, "Lean On Me," was meaningful in many ways. It was one his sister had shared with the client at a time of loss and abandonment in his childhood. It powerfully speaks of attachment, the yearning to have "somebody to lean on." Significantly, between this session and the next, memories of his sister began to flow, multiple associations and connections to their shared life together, which facilitated a deep grieving in the next session. For AEDP, what is healing is not just the intensity of the pain and grief experience that Sacks spoke of, but also the experience of doing it in the presence of a caring other, an "undoing aloneness," that makes the experience healing. It is here that I think Blimling's own deep connection to music matters as well. Music, heard together, is a shared experience, so it may have facilitated the sense of being with the other in a way that words alone were not able to do.

Of course, this was not a one-shot miracle, as long-held defenses and character patterns reasserted themselves and there followed a return to anger and condescension in therapy. The client for the most part came to sessions, but anger was again the dominant emotion and the alliance felt fragile.

There was another turning point in the $8^{\text {th }}$ session when James reported listening to a piece of music ("The Death of Falstaff") that had really touched him. This occurred after an incident of being ignored by someone he had regarded as a friend. What might have been to someone in a different emotional place a minor rejection landed on James as a crushing blow and evidence of how he would always be alone and unloved in the wake of his sister's loss. True to the experience-near approach he was using, rather than just talk about this experience, Blimling suggested bringing it into the room by asking permission to play the piece right then and there in the therapy room. This led to a powerful emotional experience where James cried deeply, expressing powerfully the depths of his loneliness, isolation and loss. This proved to be a pivotal moment, after which attendance was steady and the therapeutic alliance clearly solid. Again, the therapist "undoes aloneness" at a moment when it is precisely aloneness that feels so unbearable. The music, as a shared experience, may help the client's sense that the therapist is with him and thus is a tool of attunement. Blimling, and the music that had touched this deeply hurt place, allowed the client to open up to a depth of pain and aloneness that he rarely let himself 
experience, but rather than being in that terrible place alone, he was there with someone else. Something old, experienced in a new way, can be transformative.

The third piece of music brought to treatment shows what can happen in the wake of this "transformative emotional sequence" (Welling, 2012), the spontaneous emergence of the positive. Blimling describes James as coming in looking "chipper," and proceeding to play a song, "American Pie," which has strong positive associations to his sister. The note she sent when she gave him the album referenced a line in the song: "I hope this music can save your mortal soul." Listening and talking about it together still brought up grief at her loss, but also a profound sense of being able to take in what she had given him.

The joining through music of the first song, the depths of grief and isolation shared in the second, and the continuation of grief, but with a shared acknowledgement of the positive, the love taken in along with the sadness of the third, was followed by a revisiting of some of the pain of childhood in a visceral and affectively connected way. James brought in a French Caribbean song that translated, "Papa Where Are You?" and spoke, for the first time to anyone, of how one of the most painful things about being left alone with an abusive, alcoholic prostitute mother was his not understanding how his father could uncaringly abandon him to such a fate. So it was, poignantly through music, a journey in which the client could access the yearning for attachment, the pain of loss, the griefwork that allowed the good that was given to be taken in, and finally an increased capacity to see himself as a traumatized child who did nothing to deserve his fate. This was accompanied by symptomatic improvement - a lightening of the depression and an increasingly person-to-person engagement with the therapist which was beginning to generalize to more social engagement in his outside world.

Now comes termination, challenging even to those with good attachment histories. James' attachment history was so disrupted and painful that some might argue that it was a mistake to even engage in a short-term therapy. Yet, as I have argued elsewhere (Skean 2018), we so often now are in the position of working within time limits imposed upon us by a great variety of circumstances that we do our clients an injustice by not believing that we can often harness the innate interpersonal healing capacities to do significant work, even when time is short.

Blimling acknowledged that were he to have a second chance, handling the ending was one aspect of the treatment he might have handled differently. He had told James at the beginning of the treatment of his status as an extern and that treatment would end at a specified time, but this had not been revisited till shortly (4 sessions) before the end. Clients, particularly ones who come in as defended and closed off as James, may hear the contract in the beginning of treatment, but they do not necessarily really take it in. As they come to experience a longed-for connection, it may be even more vital to "not know." I am reminded of a very emotional scene from the movie "Antwone Fisher," where the military psychologist who had been the first person who had been a "true other" to a young man from a terribly difficult background informs him that since he is doing so much better, he is ready to be discharged from therapy. This comes as a total shock and betrayal to the client, who angrily accuses him of never caring at all, his view of the world as hostile, uncaring and neglectful simply confirmed. He eventually is able to move past that reaction, as was James in his relationship with Blimling. 
But separation remained a shock to the system, and though Blimling gave more notice than his movie counterpart, James had a powerful response of betrayal and loss. In a testament to what they had accomplished in the therapy and the strength of the relationship, James was able to come quickly to a place where he could moderate his response and reflect on the gains of the relationship. Remarkably, he was able to ask for something for himself, that instead of bringing a song to the therapist, he asked that the therapist gift him with a song in parting. So the final song of the treatment, "Pushin' On," was one that the therapist gave to the client, selected to reflect their work together, the inherent reciprocity of their dyadic interaction and Blimling's confidence in his client's ability to "push on," to continue the work of healing and growth.

\section{THE CASE OF JAMES AND THE AEDP MODEL}

In terms of AEDP and its theory development, this was a treatment more characterized by what Fosha terms her "First Avatar" than the "Second Avatar," which stresses the metaprocessing of the emotionally significant experiences of the treatment, a steady inquiry into "what was it like to do this with me?" which further installs the benefits of treatment and increases reflective capacity (Fosha, 2018). Blimling's work was more demonstrative of some of the core features of the first iteration, the focus on here and now experience, the bypassing or moderating of defenses to get to core affect, the use of the attachment relationship to "undo aloneness," the emphasis on positive affect. It was less focused on the metaprocessing of transformational experience, though there are glimmers of it when, as good clinicians do, there were check-ins about what it was like to have certain shared experiences. But it was not a conceptual focus or a goal of the treatment. Still, there may have been ways in which the music served as a kind of metalevel experience, a dyadic sharing of an experience through a "third," something outside both of them that allows them to "hang out" in a shared space of connection.

This case fits well with AEDP's (and indeed with most experiential and relational approaches) increasing emphasis on the ways in which treatment is embodied, such as affective neurobiology, including Polyvagal Theory (Porges, 2011); emotion regulation; and attachment research. Blimling talks in his paper about music as a right brain to right brain communication with the therapist. Allan Schore's significant body of work emphasizes the role our attachment system and the right brain to right brain implicit communication plays in the therapeutic alliance and in healing (Schore, 2010), noting that the therapeutic alliance is gaining increasing attention as a cornerstone of therapeutic effectiveness, one that should have pride of place alongside our therapeutic orientations and methods in evaluating and improving what we do. Quoting the APA Task Force on Evidence-Based Practice (2006):

Central to clinical expertise is interpersonal skill, which is manifested in forming a therapeutic relationship, encoding and decoding verbal and nonverbal responses, creating realistic but positive expectations and responding empathically to the patient's implicit and experiences and concerns (p. 277).

A large body of evidence has long found that the therapeutic alliance, substantially more than technical method or theoretical model, is a large contributor to outcome. Interpersonal skill cannot be manualized, but perhaps in our increasingly mind-body awareness in therapy, we can come to better know some of its ingredients. Blimling's work focuses on tracking the effect his 
incorporation of music had on attachment, memory, and affect, citing a literature that links music with each of these.

\section{THE ROLE OF MUSIC}

To return to the impact of music, a quintessential mind-body activity, McGilchrist (2009), in his major work on the roles and interactions of the left and right hemispheres of the brain, discusses a theory that singing is "a sort of instinctive musical language of intonation" ( $p$. 106) and may have preceded even speech, serving as a means of bonding as social groups became larger and bonding through physical touch was not practical. Music, by this understanding, is a body language. From this ancient evolutionary origin, it remains a powerful bonding tool for human beings. "Music has a vital way of binding people together, helping them to be aware of shared humanity, shared feelings and experiences, and actively drawing them together" (p. 104). Acknowledging that communication between human beings is not just "about things," but serves to connect us in a multitude of ways, he states: "Music is communication- but it speaks to us, not about things... it has an 'I-thou' existence, not an 'I-it' existence" (p. 106). It is this I-Thou experience that is so vital to human connection, the need to feel seen and heard. We are alone in the "I-It" condition, and we are inherently with the other in the "I-Thou." "Music, being grounded in the body, communicative of emotion, implicit, is a natural expression of the nature of the right hemisphere" (p.27).

Blimling's discussion of the ultimate effects of the integration of music on the unfolding of his case was nicely framed using the interconnected concepts of attachment, memory and affect. Music provided a useful adjunct to enhance each of these, as he lays out in his discussion of each phase/song. Attachment was facilitated throughout by the attunement through music, which also opened a path to deeper affect.

Blimling discusses the known connection between music and memory. As we know from the trauma literature, so much of what maintains trauma is memory frozen in a time and place, not integrated with the rest of who we are because it was so overwhelming at the time and still remains feared and pushed away. In their article, "Memory reconsolidation, emotional arousal, and the process of change in psychotherapy: New insights from brain science," Lane et al. (2015) discuss a body of evidence showing that when memories are reactivated, they are subject to revision. Heightened emotional arousal makes memories more available, but if arousal levels are too high, then the memories cannot be tolerated and integrated. A combination of safety within an attachment relationship and an arousal level sufficient to activate dysfunctionally held implicit memories, "safe but not too safe," as Philip Bromberg (2011, p. 189) describes it, allows these implicit memories to take form, to move into a shared space, to become more explicit.

When, for example, the safety of the relationship allowed James to access deeply painful emotions and a sense of a broken and unloved self, these old and painful memories came in the present moment with his therapist, and were experienced in a different way than they were at the time they occurred. Instead of alone and overwhelmed, the experience is now painful but experienced in the presence of a caring other. So that when the memory is re-consolidated, there 
is now an element that was not there before, a sense that life need not be faced totally alone, the seeds of self-compassion.

As stated previously, I do not believe this successful intervention argues for therapists to begin to add music to their interventions, though this certainly suggests some creative pathways for so doing. Rather its strength is that it is an example of therapist attunement, creativity, and openness to finding ways of meeting the client where he or she is - using aspects of self to achieve greater presence, to support therapist flexibility in the face of client rigidity. There are a multitude of ways for a therapist to mobilize attachment, access and reorganize memory, or deepen affect. The importance of the therapist variable has been underplayed in our psychotherapy outcome research (Norcross \& Wampold, 2019). These case examples, not only Blimling's, but those of Vigoda Gonzalez (2018) and Pass (2012), showcase ways in which therapists bring important and unique parts of who they are into the room, and in tracking client responses moment to moment and shifting interventions to adjust to this, they work towards transformative experience for their clients.

\section{REFERENCES}

APA Presidential Task Force on Evidence-Based Practice. (2006). Evidence-based practice in psychology. American Psychologist, 61, 271-285.

Blimling, G.P. (2019). The effect of integrating music listening with an attachment- and affective-focused short-term psychotherapy in an individual with relational trauma: The case of "James." Pragmatic Case Studies in Psychotherapy 15(2), Article 1, 116-166. Available: http://pcsp.libraries.rutgers.edu

Bromberg, P.M. (2011). Awakening the dreamer: Clinical journeys. New York: Routledge.

Fosha, D. (2000). The transforming power of affect: A model for accelerated change. New York: Basic Books.

Fosha, D. (2006). Quantum transformation in trauma and treatment: Traversing the crisis of healing change. Journal of Clinical Psychology, 62, 569-583.

Fosha, D. (2018). Moment-to-moment guidance of clinical interventions by AEDP's healingoriented transformational phenomenology: Commentary on Vigoda Gonzalez's (2018) Case of "Rosa." Pragmatic Case Studies in Psychotherapy 14(2), Article 1, 87-114.

Retrieved at: http://pcsp.libraries.rutgers.edu, http://dx.doi.org/10.14713/pcsp.v14i2.2038

Lane, R.D., Ryan, L., Nadel, L., \& Greenberg, L. (2015). Memory reconsolidation, emotional arousal and the process of change in psychotherapy: New insights from brain science. Behavioral and Brain Sciences, (2015), 1-64.

Lipton, B., \& Fosha, D. (2011). Attachment as a transformative process in AEDP: Operationalizing the intersection of attachment theory and affective neuroscience. Journal of Psychotherapy Integration, 21(3), 253-279.

McGilchrist, I. (2009). The master and his emissary: The divided brain and the making of the western world. New Haven, CT: Yale University Press.

Norcross, J.C., \& Wampold, B.E. (2019). Relationship and responsiveness in the psychological treatment of trauma: The tragedy of the APA Clinical Practice Guidelines. Psychotherapy, 56, 391-399. 
Pass, E. R. (2012). Combining expressive writing with an affect- and attachment-focused psychotherapeutic approach in the treatment of a single-incident trauma survivor: The case of "Grace." Pragmatic Case Studies in Psychotherapy, 8(2), Article 1, 60-112. Available: http://pcsp.libraries.rutgers.edu.

Porges, S.W. (2011). The polyvagal theory: Neurophysiological foundation of emotions, attachment, communication and self-regulation. New York: W.W. Norton.

Russell, E., \& Fosha, D. (2008). Transformational affects and core state in AEDP: The emergence and consolidation of joy, hope, gratitude, and confidence in (the solid goodness of) the self. Journal of Psychotherapy Integration, 18(2), 167-190.

Sacks, O. (2008). Musicophilia: Tales of music and the brain. New York: Knopf.

Schore, A. N. (2010). The right brain implicit self: A central mechanism of the psychotherapy change process. In J. Petrucelli (Ed.). Knowing, not-knowing and sort-of-knowing: Psychoanalysis and the experience of uncertainty, pp. 177-202. London: Karnac Books.

Skean, K.R. (2018). AEDP and cultural competence in developmental trauma treatment. Pragmatic Case Studies in Psychotherapy, 14(1), Article 3, 69-76. Available: http://pcsp.libraries.rutgers.edu/ doi: http://dx.doi.org/10.14713/pcsp.v14i1.2034

Vigoda Gonzalez, N. (2018). The merits of integrating accelerated experiential dynamic psychotherapy and cultural competence strategies in the treatment of relational trauma: The case of "Rosa. Pragmatic Case Studies in Psychotherapy, 14(1), Article 1, 1-57. Available: http://pcsp.libraries.rutgers.edu.

Welling, H. (2012). Transformative emotional sequence: Towards a common principle of change. Journal of Psychotherapy Integration, 22, 109-136. 